\title{
EFFICACY AND SAFETY OF DARUNAVIR AND ETRAVIRINE in an ANTIRetroviral Multi-EXPERIEnced Youth with Vertically HIV-1 INFECTION
}

\author{
R. Rosso ${ }^{1}$, C. Bernardini ${ }^{1}$, B. Bruzzone ${ }^{2}$, G. Secondo ${ }^{1}$, G. Icardi $^{2}$, C. Viscoli ${ }^{1}$, A. Di Biagio ${ }^{1}$ \\ ${ }^{1}$ Department of Infectious Diseases, University of Genoa, San Martino Hospital, Genoa, Italy; \\ ${ }^{2}$ Department of Health Sciences, University of Genoa, San Martino Hospital, Genoa, Italy
}

\begin{abstract}
Multiclass-drug resistance, often caused by poor treatment compliance, is a challenging problem in all categories of HIV-infected patients. Selective pressure is higher in youth for both biological and behavioral reasons. We report the case of a 15-year-old Caucasian male, with vertically acquired HIV-1 infection, who failed several lines of antiretroviral therapy and was successfully treated with darunavir/ritonavir and etravirine.
\end{abstract}

Key words: vertically acquired HIV-1 infection, multidrug resistance, adherence, darunavir, etravirine

\section{INTRODUCTION}

The use of highly active antiretroviral therapy (HAART) has dramatically improved the quality of life and overall survival of adults and children infected with HIV-1. However, suboptimal exposure to HAART (e.g. due to poor adherence, inadequate dose) can rapidly select for drug resistance mutations, and ultimately lead to virological failure. Given the dynamics of HIV viral evolution, almost complete $(>95 \%)$ adherence to combination therapy is required to maximally suppress viral load and avoid selection of resistant strains [1].

Moreover, children and adolescents seem to be more prone to selection of drug resistant variants for both biological and behavioral reasons. Plasma viral loads are much higher in children compared to adults. Therefore, children require more potent HAART to achieve virological suppression [1]. Loss of adherence, long lasting exposure to drugs and multi-drug resistance can determine a more difficult scenario to manage a therapeutical failure than in adults.

\section{CASE REPORT}

We describe a 15-year-old Caucasian male, with vertically acquired HIV-1 infection, who failed several lines of antiretroviral therapies.

He was born premature, at $22^{\text {nd }}$ week of gestation, with a spontaneous delivery, to a mother who did not assume any therapy during pregnancy. His father died few months after his birth. He remained off medications until he was 1-year-old. $\mathrm{He}$ was started monotherapy with zidovudine in 1993, didanosine in
1994, restarted zidovudine in 1995, and then was treated with stavudine in 1996. All antiretroviral therapies were done without compliance by the mother-side and were discontinued by her after some months. In 1997, the patient started the first protease inhibitor (PI)based HAART with ritonavir plus zidovudine plus lamivudine, without immuno-virological response. The same happened with all the others regimens (Table 1). In the end, he had failed four ritonavir-boosted PIbased and one nevirapine-based HAART. The patient's viral load had never been suppressed from his birth, his CD4 cells count nadir was 67 cells/ $\mu$ l (5.4\%) and his viral load zenith was 89,700 copies $/ \mathrm{mL}$.

Plasma HIV-1 RNA was measured at baseline and during therapy using a commercial assay, the Versant HIV-1 RNA 3.0 Assay (bDNA; Siemens Medical Solutions Diagnostics, Malvern, PA), with a dynamic range of 50-500,000 HIV-1 RNA copies/mL. CD4 cells count was determined by direct immunofluorescence in flow cytometry (Beckman Coulter, Fullerton, CA). Genetic analysis of the pol gene including both HIV-1 reverse transcriptase (codons 4-99) and protease (codons 35-247) regions was performed using the Trugene HIV-1 Genotyping Kit (Siemens Medical Solutions Diagnostic).

In January 2008, his clinical conditions were good, CDC status B2 (bacterial pneumonia), and height 167 $\mathrm{cm}$, weight $54 \mathrm{~kg}$, and body mass index (BMI) 19.36 . His viral load was 89,700 copies/mL and the CD4 cells count was 287 cells $/ \mu \mathrm{l}(16 \%)$. The genotype revealed the presence of D67N, K70R, Y181C, M184V, T215F, K219Q mutations within transcriptase and L10I, I13V, L24I, L33F, E34Q, M36L, F53L, I54V, L63P, G73S, V82A, N83D mutations within protease genes (Table 1). In summary, there were multiple drug resistance (MDR) mutations, which conferred highlevel resistance to most currently available antiretroviral agents, included class-resistance to the non-nucleoside reverse transcriptase inhibitors (NNRTIs).

In that period there was also a change in his family situation: the mother, who had been in jail for 6 months, was released and began to be compliant to her therapy. Therefore, after deep counseling to him and the mother, we decided to prescribe a new HAART. Darunavir/ritonavir and etravirine were provided for compassionate use by Tibotec (Cork, Ireland) and their use was approved by San Martino Hospital Ethical Committee (Genoa, Italy). The patient 
Table 1. Summary of HAART regimens and genotypic resistance tests of the patient Legend: r: ritonavir; GRT: genotypic resistance test; RTRM: reverse transcriptase mutations; PIRM: protease mutations.

\begin{tabular}{|c|c|c|c|c|c|c|}
\hline Antiretroviral Therapy & Start & End & VL & CD4+ & $\mathrm{CD} 4+(\%)$ & Reason of change \\
\hline Zidovudine & $15 / 11 / 93$ & $09 / 12 / 93$ & N.A. & 1196 & 23,2 & no compliance \\
\hline Didanosine & $10 / 12 / 93$ & $28 / 04 / 94$ & N.A. & 1328 & 24,2 & no compliance \\
\hline Zidovudine & $01 / 07 / 95$ & $07 / 06 / 96$ & N.A. & 316 & 13,2 & no compliance \\
\hline Stavudine & $28 / 06 / 96$ & $27 / 02 / 97$ & 1000 & 67 & 5,4 & no compliance \\
\hline Zidovudine + lamivudine & $28 / 02 / 97$ & $02 / 09 / 97$ & 27000 & 103 & 8,2 & virological failure \\
\hline $\begin{array}{l}\text { Zidovudine + lamivudine } \\
+ \text { ritonavir }\end{array}$ & $03 / 09 / 97$ & $20 / 03 / 98$ & 2200 & 251 & 14,2 & virological failure \\
\hline $\begin{array}{l}\text { Didanosine + nelfinavir } \\
\quad+\text { saquinavir }\end{array}$ & $12 / 10 / 98$ & $15 / 07 / 01$ & 248 & 129 & 5,6 & virological failure \\
\hline $\begin{array}{l}\text { Stavudine }+ \text { didanosine } \\
+ \text { lopinavir } / \mathrm{r}\end{array}$ & $24 / 07 / 01$ & $23 / 06 / 04$ & 45000 & 259 & 14 & virological failure \\
\hline $\begin{array}{l}\text { Didanosine }+ \text { tenofovir } \\
+ \text { lopinavir } / \mathrm{r}\end{array}$ & $24 / 06 / 04$ & $09 / 03 / 05$ & 2800 & 644 & 22 & virological failure \\
\hline $\begin{array}{l}\text { Didanosine }+ \text { tenofovir } \\
+ \text { nevirapine }\end{array}$ & $10 / 03 / 05$ & $10 / 11 / 05$ & 7700 & 465 & 20 & virological failure \\
\hline \multicolumn{7}{|c|}{ GRT: RTRM: D67N, K70R, V106A, Y181C, T215F, K219Q, F227L; PIRM: L10I, L24I, L33F, M36I/L, I54V, L63P, V82A } \\
\hline $\begin{array}{l}\text { Abacavir + lamivudine } \\
+ \text { Fos-Amprenavir/r }\end{array}$ & $11 / 11 / 05$ & $11 / 04 / 07$ & 19600 & 334 & 17 & no compliance \\
\hline \multicolumn{7}{|c|}{ GRT: RTRM: D67N, K70R, Y181C, M184V, T215F, K219Q; PIRM: L10I, L24I, L33F, M36L, F53L I54V, L63P, G73S, V82A } \\
\hline $\begin{array}{l}\text { Abacavir + lamivudine } \\
+ \text { lopinavir/r }\end{array}$ & $12 / 04 / 07$ & $12 / 02 / 08$ & 14800 & 410 & 17 & virological failure \\
\hline \multicolumn{7}{|c|}{$\begin{array}{c}\text { GRT: RTRM: D67N, K70R, Y181C, M184V, T215F, K219Q; PIRM: L10I, I13V, L24I, L33F, M36L, F53L, I54V, L63P, G73S } \\
\text { V82A }\end{array}$} \\
\hline $\begin{array}{c}\text { Abacavir }+ \text { lamivudine } \\
+ \text { darunavir } / \mathrm{r}+\text { etravirine }\end{array}$ & $13 / 02 / 08$ & ongoing & 89700 & 287 & 16 & ongoing \\
\hline
\end{tabular}

started these new drugs together with fixed dose abacavir/lamivudine combination. Based on the weight, he could take the adult dose of each drug.

After one month of therapy, viral load became undetectable for the first time in the patient's life. During the first year of follow-up, viral load remained stably undetectable, meanwhile CD4 cells count and percentage increased to 706 cells $/ \mathrm{mL}$ and $18 \%$, respectively. Laboratory data remained within normal range showing no hepatic and metabolic toxicity. In particular, median aspartate aminotransferase (AST, normal range, $\mathrm{r}, 0-40$ ) was $33 \mathrm{U} / \mathrm{L}$, alanine aminotransferase (ALT, r 0-40) $23 \mathrm{U} / \mathrm{L}, \gamma$ glutamyltranspeptidase (GGT, r 11-50) $28 \mathrm{U} / \mathrm{L}$, plasma glucose (r 65-110) $83 \mathrm{mg} / \mathrm{dL}$, glycated haemoglobin (r 4.3-5.8) 5.1\%, insulin levels ( $\mathrm{r}$ 2.0-25) $5.8 \mathrm{mU} / \mathrm{L}$, triglycerides (r 4-170) $110 \mathrm{mg} / \mathrm{dL}$, total cholesterol (r 130-200) $177 \mathrm{mg} / \mathrm{dL}$, HDL-cholesterol $31.5 \mathrm{mg} / \mathrm{dL}$, and LDL-cholesterol $118 \mathrm{mg} / \mathrm{dL}$.

The new regimen was well tolerated and adherence to treatment was reported excellent throughout the entire period, monitored by performing monthly outpatient's visit and calling the patient every two weeks.

\section{DisCUSSION}

Strategies for the management of HIV-infected patients with extensive previous treatment and drug resistance are very limited, especially in children and adolescents. As a matter of fact, in this population the use of experimental agents, with a close follow-up, must be considered. Besides, a careful monitoring of adherence is needed for a successful therapy.

This case report has examined the successful inhibition of viral replication in a MDR patient who exhibited very poor compliance with previous therapies. The treatment regimen consisted of a new and recently approved combination used in adults, based on darunavir/ritonavir and etravirine, in addition to a well-known nucleoside reverse transcriptase inhibitor backbone [2]. In the first year of therapy the CD4 cells count increased and viral load fell to undetectable levels. Tolerability was good and no serious adverse events were recorded. The patient is still following this regimen.

This antiretroviral regimen has been chosen in consequence of the poor compliance of the patient showed during the past years. Fixed dose abacavir/lamivudine combination was used as backbone. Abacavir seemed to maintain a partial activity, at least according to some interpretation alghorithms, and was preferred to tenofovir which would have been a safer choice based on mutational pattern, by reason of previously tested poor tolerability (proteinuria). Lamivudine was maintained in order to affect viral fitness.

Darunavir, in combination with low-dose ritonavir, approved in adult since July 2007 in Italy, has shown potent antiviral activity and good tolerability in threeclass-experienced HIV-infected patients with limited 
or no treatment options [3]. Recent reports have highlighted that 11 mutations of which 5 major (I50V, $\mathrm{I} 54 \mathrm{~L} / \mathrm{M}, \mathrm{L} 76 \mathrm{~V}$ and $\mathrm{I} 84 \mathrm{~V}$ ) and 6 minor (V11I, V32I, L33F, I47V, G73S and L89V), selected in patients failing it, are associated with decreased susceptibility to darunavir [4].

In our patient the presence of three minor mutations (L33F, G73S and L89V) had not compromised the efficacy of the drug. This fact, probably, confirms the importance of number, type, pattern of association and weight of mutations.

Etravirine, currently available in Italy only in the expanded access program (TMC125-c214), is a second generation NNRTI that appears to be effective against a variety of HIV viruses that are resistant to efavirenz and nevirapine. Three or more mutations are associated with decreased virologic response [5]. In our patient there was only one mutation (Y181C), but with a weight factor of 2.5 , using the weighted genotypic score. This score has been provided by Vingerhoets J et al. analyzing the database of the patients enrolled in the DUET-1 and DUET-2 trials [6]. The sum of the different weighted factors predicts virological response to etravirine, and in our patient this should have been an intermediate response.

One of the first studies, assessing the role of etravirine and darunavir in HIV-1-infected subjects with no treatment options, showed highly effective virological and immunological responses over 24 weeks of therapy with no new safety concerns or unexpected pharmacokinetic interactions [7].

Enfuvirtide could be another good choice, also because it is approved for pediatric use, but its way of administration, with often-intolerable subcutaneous injection site reactions, would have never been accepted from the patient. The genotypic test showed also a susceptibility to tipranavir (one major I54V and one accessory mutation L33F), confirmed from the tipranavir-mutation-score $(\mathrm{Score}=1)$ that could allow us to choose that drug in the new regimen [8]. We decided, however, to choose darunavir, because etravirine should not be administered with tipranavir [9].

In conclusion, this case report underlines the importance of the continuous development of new drugs and the great need of their approval also for pediatric/adolescent use, as clinicians will continue to encounter an increasing number of MDR HIV-infected youths, who have extensive experience with previous treatments. It is, indeed, of extreme importance to evaluate the compliance with all the available methods (e.g. self reporting calendars, records of missed doses, pill counts, interview questionnaires, therapeutic drug monitoring), knowing that the most common cause of treatment failure is insufficient adherence, which can be found in $25-30 \%$ of children [10].

In particular, adolescents with vertically acquiredHIV- infection may require complicated regimens, because of significant antiretroviral treatment experience and poor adherence.

So it is clear the importance of having parents and/or caregivers who can do an accurate and consistent monitoring and improve the children/adolescent's compliance.

\section{REFERENCES}

1. Chen TK, Aldrovandi GM. Review of HIV Antiretroviral Drug Resistance. Pediatr Infect Dis J. 2008 Aug; 27(8): 749-52.

2. Green H, Gibb DM, Walker AS, Pillay D, Butler K, Candeias F, Castelli-Gattinara G, Compagnucci A, Della Negra M, de Rossi A, Feiterna-Sperling C, Giaquinto C, Harper L, Levy J, Saidi Y, Wintergerst U; Paediatric European Network for the Treatment of AIDS (PENTA). Lamivudine/abacavir maintains virological superiority over zidovudine/lamivudine and zidovudine/abacavir beyond 5 years in children. AIDS. 2007 May 11; 21(8): 947-55.

3. Katlama C, Esposito R, Gatell JM, Goffard JC, Grinsztejn B, Pozniak A, Rockstroh J, Stoehr A, Vetter N, Yeni P, Parys W, Vangeneugden T; the POWER 1 study group. Efficacy and safety of TMC114/ritonavir in treatment-experienced HIV patients: 24-week results of POWER 1. AIDS. 2007 Feb 19; 21(4): 395-402.

4. Poveda E, de Mendoza C, Martin-Carbonero L, Corral A, Briz V, González-Lahoz J, Soriano V. Prevalence of darunavir resistance mutations in HIV-1-infected patients failing other protease inhibitors. J Antimicrob Chemother. 2007 Oct; 60(4): 885-8.

5. Madruga JV, Cahn P, Grinsztejn B, Haubrich R, Lalezari J, Mills A, Pialoux G, Wilkin T, Peeters M, Vingerhoets J, de Smedt G, Leopold L, Trefiglio R, Woodfall B; DUET1 study group. Efficacy and safety of TMC-125 (etravirine) in treatment-experienced HIV-1-infected patients in DUET-1: 24-week results from a randomised, doubleblind, placebo-controlled-trial. Lancet. 2007 Jul 7; 370 (9581):29-38,

6. Vingerhoets, J., M. Peeters, H. Azjin, L. Tambuyzer, A. Hoogstoel, S. Nijs, M. de Bethune, and G. Picchio. An update of the list of NNRTI mutations associated with decreased virological response to etravirine: multivariate analysis on the pooled DUET-1 and DUET-2 clinical trial data [abstract 24]. Antivir Ther. 2008; 13: Suppl 3:A26.

7. Boffito M, Winston A, Jackson A, Fletcher C, Pozniak A, Nelson M, Moyle G, Tolowinska I, Hoetelmans R, Miralles D, Gazzard B. Pharmacokinetics and antiretroviral response to Darunavir/ritonavir and Etravirine combination in patients with high-level viral resistance. AIDS. 2007 Jul 11; 21(11): 1449-55.

8. Poveda E. New resistance score for tipranavir. AIDS Rev. 2008 Apr-Jun; 10(2): 127.

9. FDA - Intelence Prescribing Information. January 2008, pp. 7-8. Available at:

http://www.fda.gov/cder/foi/label/2008/022187lbl.pdf. Accessed 25 October 2008.

10. Van Dyke RB, Lee S, Johnson GM, Wiznia A, Mohan K, Stanley K, Morse EV, Krogstad PA, Nachman S; Pediatric AIDS Clinical Trials Group Adherence Subcommittee Pediatric AIDS Clinical Trials Group 377 Study Team. Reported adherence as a determinant of response to highly active antiretroviral therapy in children who have human immunodeficiency virus infection. Pediatrics. 2002 Apr; 109(4): e61.

Received: January 30, 2009 / Accepted: February 3, 2009

Address for correspondence:

Raffaella Rosso MD, PhD

Dept. of Infectious Diseases

University of Genoa, San Martino Hospital

Largo R. Benzi 10

16132, Genova, Italy

Fax: $\quad+390103537680$

Phone: +390105555142

E-mail: Raffaella.Rosso@unige.it 